\title{
Effect of methanolic extract from Capsicum annuum against the multiplication of several Babesia species and Theileria equi on in vitro cultures, and Babesia microti in mice
}

\author{
Mohamed Abdo Rizk ${ }^{1,2+}$, Shimaa Abd El-Salam El-Sayed ${ }^{1,3+}$ (D) Mostafa Al-Araby $^{4}$ (D) and Ikuo Igarashi1 ${ }^{10}$
}

\begin{abstract}
1. National Research Center for Protozoan Diseases, Obihiro University of Agriculture and Veterinary Medicine, InadaCho, Obihiro, Hokkaido 080-8555, Japan; 2. Department of Internal Medicine and Infectious Diseases, Faculty of Veterinary Medicine, Mansoura University, Mansoura 35516, Egypt; 3. Department of Biochemistry and Chemistry of Nutrition, Faculty of Veterinary Medicine, Mansoura University, Mansoura 35516, Egypt; 4. Department of Parasitology, Faculty of Veterinary Medicine, Mansoura University, Mansoura 35516, Egypt.

${ }^{\dagger}$ These authors contributed equally to this study.

Corresponding authors: Mohamed Abdo Rizk, e-mail: dr_moh_abdo2008@mans.edu.eg; Ikuo Igarashi, e-mail: igarcpmi@obihiro.ac.jp

Co-authors: SAEE: shimaa_a@mans.edu.eg, MA: E-mail: alarabyma@yahoo.com

Received: 26-08-2021, Accepted: 23-12-2021, Published online: 20-01-2022
\end{abstract}

doi: www.doi.org/10.14202/vetworld.2022.76-82 How to cite this article: Rizk MA, El-Sayed SAE, Al-Araby M, Igarashi I (2022) Effect of methanolic extract from Capsicum annuum against the multiplication of several Babesia species and Theileria equi on in vitro cultures, and Babesia microti in mice, Veterinary World, 15(1): 76-82.

\begin{abstract}
Background and Aim: Piroplasmosis is a serious disease that infects animals, inflicting significant economic losses in the livestock industry and animal trade worldwide. Anti-piroplasm drugs now on the market have demonstrated host toxicity and parasite resistance. As a result, developing more effective and safer anti-piroplasm drugs becomes an urgent issue. This study aimed to evaluate the inhibitory effect of Capsicum annuum methanolic extract (CA) against the growth of Babesia bovis, Babesia divergens, Babesia caballi, and Theileria equi in vitro and against B. microti in mice.
\end{abstract}

Materials and Methods: Fluorescence-based SYBR Green I assay was used to evaluate CA's inhibitory effect in vitro and in vivo when used either as a monotherapy or combined with diminazene aceturate (DA). The hematological parameters (HCT, hemoglobin, and red blood cells counts) were determined in the blood of mice every $96 \mathrm{~h}$ using Celltac $\alpha$ MEK-6450 electronic hematology analyzer.

Results: The in vitro growth of $B$. bovis, B. divergens, T. equi, and B. caballi was inhibited by CA in a dose-dependent manner with $\mathrm{IC}_{50}$ values of $4.87 \pm 1.23,44.11 \pm 8.03,8.23 \pm 2.54$, and $1.26 \pm 0.50 \mathrm{mg} / \mathrm{mL}$, respectively. In $B$. microti-infected mice, a combination therapy consisting of CA and a low dose of DA showed a significant $(\mathrm{p}<0.05)$ inhibition of $B$. microti growth nearly similar to those obtained by treatment with the full dose of DA.

Conclusion: The obtained results indicate that CA might be a promising medicinal plant for treating babesiosis, especially when used with a low dose of DA.

Keywords: Babesia, Capsicum annuum, combination therapy, in vitro, in vivo, Theileria.

\section{Introduction}

Tick-borne parasites Babesia and Theileria infect the erythrocytes of animals, causing major economic losses in the livestock industry and animal trade worldwide [1]. Fever, malaise, jaundice, hemoglobinuria, and mortality are among the condition's symptoms [2]. The most common sources of infection in cattle are Babesia bovis and Babesia divergens, which result in severe losses in animal health and productivity [2]. Theileria equi and Babesia caballi are the most common causes of equine illness [3]. There are no acceptable laboratory experimental animals for bovine Babesia and equine piroplasm infections.

Copyright: Rizk, et al. Open Access. This article is distributed under the terms of the Creative Commons Attribution 4.0 International License (http://creativecommons.org/licenses/by/4.0/), which permits unrestricted use, distribution, and reproduction in any medium, provided you give appropriate credit to the original author(s) and the source, provide a link to the Creative Commons license, and indicate if changes were made. The Creative Commons Public Domain Dedication waiver (http://creativecommons.org/ publicdomain/zero/1.0/) applies to the data made available in this article, unless otherwise stated.
Alternatively, a rodent Babesia model with B. microti is used to evaluate antibabesial drugs against babesiosis. The inhibitory effect of recently developed drugs should be evaluated in laboratory animals to identify the possible side effects before they are implemented in the field [4].

Anti-piroplasm medications currently on the market have shown toxicity to the host in the form of imidocarb dipropionate and resistance from the treated parasite in the form of diminazene aceturate (DA) [1]. Therefore, finding more effective and safer anti-piroplasm medicines becomes a priority. In this case, natural phytochemicals could be a potential alternative. Following this pattern, Capsicum annuиm (CA), a member of the Solanaceae family, is generally considered safe for use in food by the US Food and Drug Administration [5]. CA has various medical and culinary applications [6]. Furthermore, it has been used as a food additive, as well as an antiseptic, counterirritant, appetite stimulator [6], antioxidant [7], and immunomodulatory [8] in traditional medicine 
for treating cough, toothache, sore throat, parasitic infections, rheumatism, and wound healing $[6,9]$. It has also been suggested to have antibacterial and anticancer properties [8]. In an in vitro research, extracts from the leaves of CA caused Schistosoma mansoni cercaria to die within $15 \mathrm{~min}$. Water-soluble unsaturated molecules from oils or their hydrolysis products appeared to be the active factors [10].

There has been no previous research on the effectiveness of CA extracts as an anti-piroplasm agent. This study aimed to look into the CA's potential as an anti-piroplasm agent against the in vitro development of bovine and equine Babesia/Theileria species, as well as $B$. microti in mice.

\section{Materials and Methods}

\section{Ethical approval}

The stud was approved by the Animal Care and Use Committee at the Obihiro University of Agriculture and Veterinary Medicine (Approval No. 27-65). All experiments were carried out following the Ministry of Education's Culture, Sports, Science, and Technology, Japan Fundamental Guidelines for the Proper Conduct of Animal Experiments and Related Activities at Academic Research Institutions.

\section{Study period and location}

The study was conducted from July 2018 to November 2019 at National Research Center for Protozoan Diseases, Obihiro University of Agriculture and Veterinary Medicine, Japan.

\section{Chemicals}

SYBR Green I (SGI) is a nucleic acid stain (Lonza, Rockland, USA; 10,000x). A lysis buffer was made ahead of time and kept at $4^{\circ} \mathrm{C}$. CA powder was purchased from iherb.com. Methanol was $99.8 \%$ pure (Wako Pure Chemical Industries, Ltd., Osaka, Japan) by dissolving $100 \mathrm{mg}$ (crude extract) in $1 \mathrm{~mL}$ of dimethyl sulfoxide (DMSO) (Wako Pure Chemical Industries, Ltd.), we were able to make a stock methanolic extract of CA solution. DA was bought from Ganaseg, Ciba-Geigy Japan Ltd., Tokyo, Japan.

\section{CA methanolic extract preparation}

CA powder $(10 \mathrm{~g})$ was dissolved in $50 \mathrm{~mL}$ methanol and then incubated for 3 days at $30^{\circ} \mathrm{C}$. After that, the resultant product was filtered using Whatman filter paper No. 1. The resulting extract was concentrated and lyophilized using a rotary evaporator (BUCHI ${ }^{\circledR}$ Rotavapor R-200/205, Flawil, Switzerland) under decreased pressure at $40^{\circ} \mathrm{C}$ and a freeze-dry vacuum system (Labconco, Kansas, MO, USA) [11,12].

\section{Determination of the toxic effect of CA methanolic extract on host erythrocytes}

CA toxicity to host erythrocytes was assessed as previously described [13]. For $3 \mathrm{~h}$ at $37^{\circ} \mathrm{C}$, bovine and equine erythrocytes were prepared with either media alone or media with CA methanolic extract $(100 \mathrm{mg} / \mathrm{mL})$. Then, using drug-free media, a triple wash cycle of red blood cells (RBCs) was conducted, followed by the cultivation of Babesia parasites in the washed RBCs for $72 \mathrm{~h}$, and the parasite's growth was evaluated in both pre-treated and control untreated cells. Each drug concentration was tested in three wells and three different trials for each parasite species.

\section{In vitro growth inhibition and viability assays}

The chemotherapeutic efficacy of CA against $B$. bovis (Texas strain) [14], B. divergens (German strain) [15], B. caballi [3], and T. equi (US Department of Agriculture) [3] was studied. According to AbouLaila et al. [13] and Rizk et al. [14], parasites were cultivated in species-specific RBCs. CA's capacity to inhibit Babesia/Theileria growth was investigated using a fluorescence assay and SGI stain $[14,16]$. Parasitized RBCs (pRBCs) were cultured with various Babesia species using media alone or with CA concentrations ranging from 0.5 to $100 \mathrm{mg} / \mathrm{mL}$ in two 96-well plates (Nunc, Roskilde, Denmark). M199 medium (Sigma-Aldrich, Tokyo, Japan) was used to culture $B$. bovis and T. equi parasites, while RPMI 1640 medium (Sigma-Aldrich) was used for $B$. divergens and B. caballi. A preliminary investigation was conducted to determine the concentrations. The commonly used antibabesial drug, DA was used as a positive control drug with concentrations ranging from 0.25 to $10 \mathrm{~g} / \mathrm{mL}$. Cultures without the medication and cultures containing only DMSO $(0.3 \%$ for $\mathrm{CA})$ and DDW $(0.02 \%$ for DA) were generated as negative experimental controls. For each drug concentration, 96-well plates were used to cultivate RBCs parasitized with bovine and equine Babesia/Theileria parasites at $1 \%$ parasitemia using $2.5 \%$ HCT for $B$. bovis and $5 \%$ HCT for other Babesia and Theileria parasites for 4 days. On the $4^{\text {th }}$ day of culture, a $100 \mu \mathrm{L}$ lysis buffer containing $2 \times$ SG I was added to each well on the first plate. Next, plates were covered with aluminum foil and incubated for $6 \mathrm{~h}$ at room temperature $\left(34^{\circ} \mathrm{C}\right)$. A fluorescence plate reader (Fluoroskan Ascent; Thermo Labsystems, USA) was used for estimating the fluorescence values at $485 \mathrm{~nm}$ and $518 \mathrm{~nm}$ excitation and emission wavelengths. Gain values were set to 100 . Finally, $\mathrm{IC}_{50}$ values were calculated. While the second plate was used to determine the regrowth of the tested parasites after discontinuing the in vitro treatment using viability assay [15].

\section{CA and antibabesial drugs combination in vitro}

Combining CA treatments with ordinarily utilized antibabesial drug, DA was evaluated against the in vitro cultures of $B$. divergens and $T$. equi (Babesia and Theileria spp. displayed the most elevated $\mathrm{IC}_{50}$ among screened parasites). As recently described, combined proportions for CA/DA (M1-M8) were set up $[13,17]$. Combination ratios were determined based on the $\mathrm{IC}_{50 \text { s }}$. Drug-free cultures were employed as a negative control. Three independent trials were conducted, each comprising three triplicate studies with a 4-day medication combination utilizing 5\% HCT. The fluorescence levels were calculated on the 
$4^{\text {th }}$ day of culture after adding lysis buffer to each medication combination on the 96 -well plates as mentioned above.

\section{In vivo inhibitory effect of CA on the growth of $B$. microti in mice}

The CA in vivo inhibition test for $B$. microti (Munich strain) [17] in BALB/c mice 2 months old (from CLEA Japan, Tokyo, Japan) was performed twice using a fluorescent-based SGI assay [18]. All mice were held under pathogen-free conditions. Twenty-five female BALB/c mice were divided equally into five groups. All mice were intraperitoneally infected with $1 \times 10^{7} \mathrm{~B}$. microti RBCs. Mice in the first group remained without infection and were used as the negative control. The parasitemia was observed in the infected mice, and once it reached around $1 \%$, B. microti-infected mice received the treatment for 5 days. In the positive treatment control mice (second group), mice were infused with $\mathrm{I} / \mathrm{P}$ dosages of DMSO in phosphate buffer saline $(0.02 \%)$. DA was used as a control drug and administrated subcutaneously to the mice in the third group at a dose rate of $25 \mathrm{mg} / \mathrm{kg}$. CA was administered orally either alone at a dose rate of $100 \mathrm{mg} / \mathrm{kg}$ or combined with a subcutaneous dose of DA at a dose rate of $50 \mathrm{mg} / \mathrm{kg} \mathrm{CA}$ and $12.5 \mathrm{mg} / \mathrm{kg}$ DA to the mice in the fourth and fifth groups, respectively. The inhibitory impacts of each specific drug on $B$. microti growth were examined as described previously [18].

\section{Anemia monitoring in treated mice}

The hematological parameters (HCT, hemoglobin [HGB], and RBC counts) were determined in the blood of all mice each $96 \mathrm{~h}$ utilizing Celltac $\alpha$ MEK6450 electronic hematology analyzer (Nihon Kohden Enterprise, Tokyo, Japan).

\section{Statistical analysis}

GraphPad Prism (version 5.0 for Windows; GraphPad Software, Inc., San Diego, CA, USA) was used to calculate the significant differences between examined groups using a one-way analysis of variance test. $\mathrm{p}<0.05$ was considered statistically significant.

\section{Results}

\section{CA methanolic extract represses the in vitro develop- ment of Babesia and Theileria}

The calculated $\mathrm{IC}_{50} \mathrm{~S}$ and $\mathrm{IC}_{90} \mathrm{~S}$ revealed that the CA mainly affects the growth of $B$. caballi, and $B$. bovis followed by $T$. equi (Tables- 1 and $\mathrm{S} 1$ ). $B$. divergens presented the most elevated $\mathrm{IC}_{50}$ among screened parasites (Tables-1 and $\mathrm{S} 1$ ). The in vitro development of B. bovis, B. divergens, and B. caballi was collectively repressed $(\mathrm{p}<0.05)$ by $1 \mathrm{mg} / \mathrm{mL} \mathrm{CA}$ (Figure-1a-d). Moreover, $10 \mathrm{mg} / \mathrm{mL}$ of CA treatment collectively restrained $(\mathrm{p}<0.05) T$. equi development (Figure-1c). The in vitro regrowth of B. bovis, B. divergens, and T. equi was repressed in the resulting viability test at a concentration of $25 \mathrm{mg} / \mathrm{mL}, 100 \mathrm{mg} / \mathrm{mL}$, and $50 \mathrm{mg} / \mathrm{mL}$ CA, individually (Table-2). Notably,
B. caballi treatment in vitro culture with $10 \mathrm{mg} / \mathrm{mL}$ CA forestalled parasite regrowth (Table-2). DA halted the regrowth of screened piroplasm parasites at $0.25 \mu / \mathrm{mL}$ (Table-S2). The noticed non-significant contrast $(p>0.05)$ between the positive control well containing the DMSO and untreated wells, showing that the diluent did not impact the CA methanolic extract viability. In addition, erythrocyte pre-treatment with a high centralization of CA methanolic extract $25 \mathrm{mg} / \mathrm{mL}$ does not influence either the parasite development example or erythrocyte morphology when contrasted with the non-treated erythrocytes by light magnifying instrument (data not shown).

\section{DA improved the in vitro adequacy of CA methanolic separate}

Several combinations of CA with DA on piroplasm parasites indicated the low in vitro susceptibly to CA ( $B$. divergens and T. equi) among screened parasites have been assessed. CA/DA mix showed higher inhibitory effects on $B$. divergens, and T. equi development than those noticed using DA monotherapy at M5 (0.25 IC I0 $_{50}$ CA:0.75 IC ${ }_{50}$ DA) and M6 (0.25 IC CA:0.50 IC ${ }_{50} \mathrm{DA}$ ), individually (Table-3). Such findings confirmed the potential anti-piroplasm impact of $\mathrm{CA}$, especially when administered in lower dosages with the regularly used antibabesial drug DA.

\section{CA/DA clears B. microti infection in mice}

The in vivo inhibitory effect of the CA was considered in contrast to B. microti in a mouse model. In correlation with the positive benchmark group, a considerable hindrance $(p<0.05)$ in the produced fluorescence signals was observed in CA monotherapy-treated mice on days $14,16,18$, and 20 p.i. (Figure-2). Notably, the inhibition within the fluorescence signals was comparable in mice treated with CA/DA combination and those from mice treated with ful 1 dose $(25 \mathrm{mg} / \mathrm{kg})$ DA at multiday p.i. (Figure-2). Oral administration of $50 \mathrm{mg} / \mathrm{kg} \mathrm{CA}$, when administered along with a subcutaneous dose of $12.5 \mathrm{mg} / \mathrm{kg}$ DA, caused $49.17 \%$ and $74.48 \%$ inhibition rates in B. microti growth on 10 and 12 days pi, respectively. In contrast, $25 \mathrm{mg} / \mathrm{kg}$ DA monotherapy showed $54.46 \%$ and $73.42 \%$ inhibition of parasite growth on days 10 and 12 pi (Figure-3).

Table-1: IC $_{50}$ values of Capsicum annuum evaluated for bovine Babesia and equine Babesia and Theileria parasites

\begin{tabular}{lc}
\hline Organism & IC $_{\mathbf{5 0}}(\mathbf{m g} / \mathbf{m L})^{\mathbf{a}}$ \\
\hline B. bovis & $4.87 \pm 1.23_{(0.25)}$ \\
B. divergens & $44.11 \pm 8.03_{(0.18)}$ \\
T. equi & $8.23 \pm 2.54_{(0.31)}$ \\
B. caballi & $1.26 \pm 0.50_{(0.39)}$ \\
\hline
\end{tabular}

${ }^{a} \mathrm{IC}_{50}$ values for Capsicum annuum was calculated based on the growth inhibitions determined using fluorescence-based assay in three separate experiments. Drug concentration was made in triplicate in each experiment, and the final obtained $\mathrm{IC}_{50}$ represents the mean and standard deviation of three separate experiments. The coefficient of variation data is shown as a subscript without a multiplication step. 


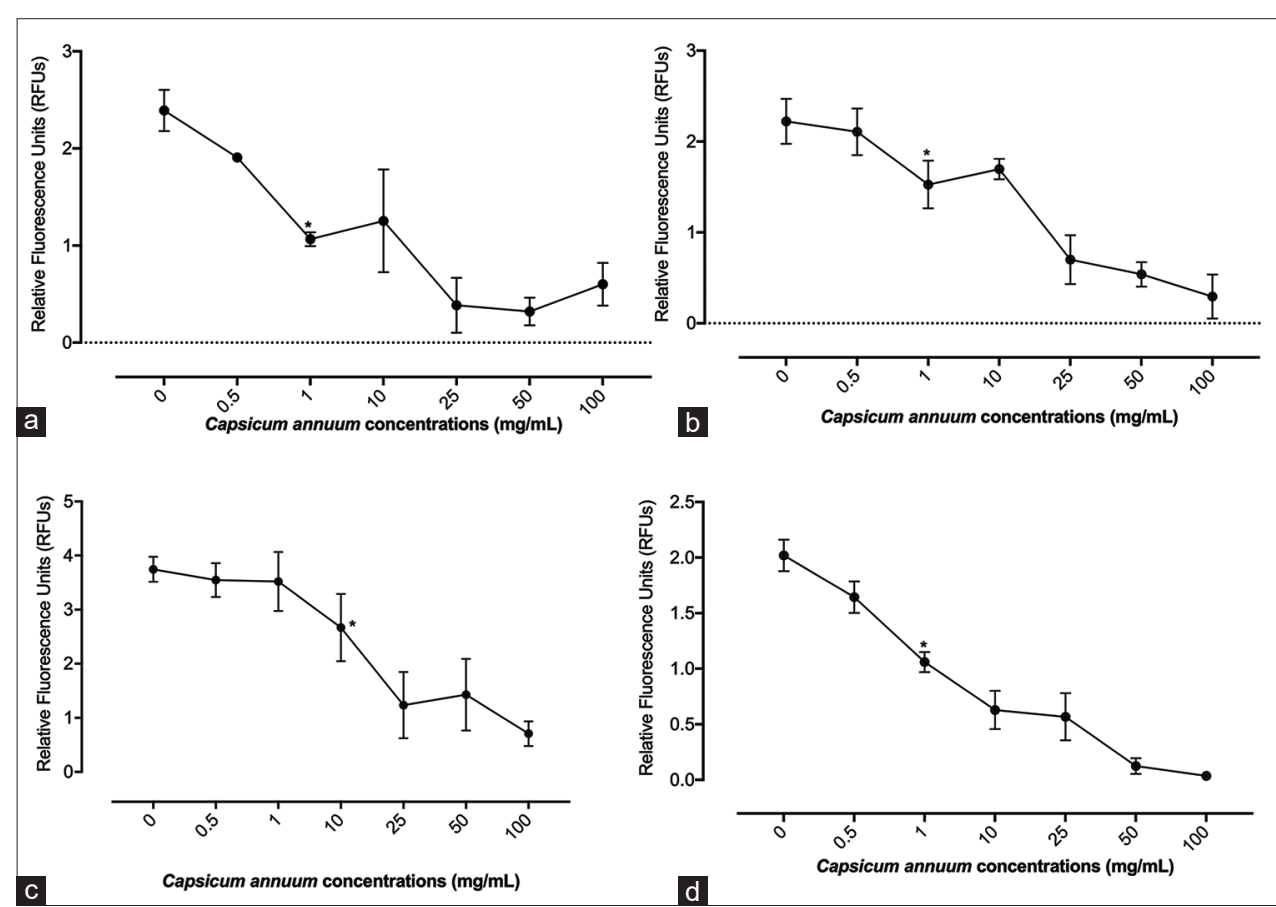

Figure-1: Inhibitory effect of Capsicum annuum on Babesia bovis, Babesia divergens, Theileria equi, and Babesia caballi on the $4^{\text {th }}$ day of treatment. (a) B. bovis. (b) Babesia bigemina. (c) $T$. equi. (d) B. caballi. Each value represents the mean \pm standard deviation of triplicate trials after subtracting the background fluorescence for non-parasitized red blood cells. Asterisks indicate a significant difference (analysis of variance; $* p<0.05$ ) between the Capsicum annuum-treated and the control cultures.

Table-2: Viability test results of Capsicum annuum evaluated for bovine Babesia and equine Babesia and Theileria parasites

\begin{tabular}{lccccccc}
\hline Drug & \multicolumn{7}{c}{ Drug concentrations $\mathbf{( m g / m L})^{\mathbf{a}}$} \\
\cline { 2 - 9 } & $\mathbf{P C}$ & $\mathbf{0 . 5}$ & $\mathbf{1}$ & $\mathbf{1 0}$ & $\mathbf{2 5}$ & $\mathbf{5 0}$ & $\mathbf{1 0 0}$ \\
\hline B. bovis & $254.11 \pm 73.50$ & $252.07 \pm 68.42$ & $249.82 \pm 63.66$ & $265.41 \pm 44.56$ & $91.23 \pm 23.08^{*}$ & $85.55 \pm 11.07^{*}$ & $21.08 \pm 8.11^{*}$ \\
B. divergens & $301.67 \pm 45.20$ & $304.51 \pm 30.15$ & $299.33 \pm 35.41$ & $294.33 \pm 34.11$ & $289.22 \pm 24.90$ & $299.11 \pm 33.20$ & $79.34 \pm 21.30 *$ \\
T. equi & $345.55 \pm 65.33$ & $332.11 \pm 52.04$ & $342.67 \pm 48.52$ & $344.22 \pm 39.67$ & $330.08 \pm 42.57$ & $132.44 \pm 22.36^{*}$ & $45.31 \pm 17.88^{*}$ \\
B. caballi & $204.01 \pm 23.56$ & $205 \pm 20.11$ & $202.21 \pm 24.30$ & $103.23 \pm 9.18^{*}$ & $91.33 \pm 15.43^{*}$ & $51.37 \pm 12.35^{*}$ & $12.87 \pm 4.09^{*}$ \\
\hline
\end{tabular}

aEach value was calculated using fluorescence-based assay in three separate experiments. Each concentration of the drug was made in triplicate in each experiment, and the final obtained fluorescence value represents the mean and standard deviation of three separate experiments after subtraction of the background fluorescence for non-parasitized RBCs and multiplied by $100 .{ }^{*} P<0.05$ statistically significant differences between the Capsicum annuum -treated and control groups.

\section{CA/DA treats hemolytic sickliness brought about by B. microti infection in mice}

Interestingly, treatment of mice with CA and a low portion of DA standardized the evaluated hematological factors practically like those treated with $25 \mathrm{mg} / \mathrm{kg}$ DA (Figure-4). Contrastly, a significant decrease $(p<0.05)$ in RBCs included in mice treated with CA monotherapy in examination with negative control mice (got neither disease nor treatment) on days 4-24 p.i. like those detected in positive control mice (Figure-4a). Comparatively, in examination with negative control mice, a significant decrease $(\mathrm{p}<0.05)$ in HGB level and HCT \% on days 8 and 10 in mice treated with CA monotherapy (Figure- $4 \mathrm{~b}$ and $\mathrm{c}$ ). Such discoveries showed the promising antibabesial adequacy of CA/DA mix treatment.

\section{Discussion}

Extraction is the most common method for extracting bioactive chemicals from biomass materials.
The extraction procedure aims to obtain the maximum biological activity from the extracts while maximizing the number of target components. The extraction solvent and the extraction technique have an impact on the extraction yield and biological activity of the final extract $[19,20]$. Many solvents have been used to extract bioactive chemicals from plant material, including methanol, ethanol, acetone, and water. Because of the diversity of bioactive chemicals found in plant materials and their varying solubility qualities in several solvents, the best solvent for extraction is determined by the plant materials and the compounds to be extracted. Truong et al. [20] reported that methanol is the most effective solvent for obtaining an extraction from Severinia buxifolia over other solvents, including distilled water, ethanol, chloroform, dichloromethane, and acetone. Using methanol resulted in the highest extraction yield $(33.2 \%)$ and the highest content of 
phenolic, flavonoid, alkaloid, and terpenoids from Severinia buxifolia. In addition, the extract obtained from methanol showed high antioxidant capacity and in vitro anti-inflammatory activity [20]. Subsequently, those authors recommended methanol as the optimal solvent to obtain high content of phytochemical constituents and high antioxidants constituents for usage in pharmacognosy. Therefore, in this study, we evaluated the inhibitory effect of CA's methanol extract on $B$. bovis, $B$. divergens, $T$. equi, and $B$. caballi in vitro and $B$. microti development in vivo.

B. caballi and B. bovis were the touchiest to CA, trailed by $T$. equi and $B$. divergens. The $\mathrm{IC}_{50}$ upsides of CA for Babesia and Theileria parasites were higher than those of recently screened restorative plants,

Table-3: Growth inhibition effect of Capsicum annuum/ diminazene aceturate combinations on Babesia divergens and Theileria. equi

\begin{tabular}{|c|c|c|}
\hline \multirow[t]{2}{*}{ Group } & \multicolumn{2}{|c|}{ Fluorescence values (mean \pm SD) } \\
\hline & B. divergens & T. equi \\
\hline Control & $243.05 \pm 7.10$ & $325.15 \pm 12.34$ \\
\hline $\mathrm{DA} \mathrm{IC} \mathrm{I}_{50}$ & $120.11 \pm 6.43$ & $152.11 \pm 4.01_{(0.03)}^{(0.04)}$ \\
\hline M1 $(-:-)$ & $15.24 \pm 0.97 * *$ & $3.22 \pm 0.98 * *$ \\
\hline M2 (-: 1/2) & $19.21 \pm 4.19 * *$ & $9.14 \pm 0.13 * *$ \\
\hline M3 $(1 / 2:-)$ & $22.12 \pm 3.18 * *$ & $11.34 \pm 1.13 * *$ \\
\hline M4 $(1 / 2: 1 / 2)$ & $37.17 \pm 2.14 * *$ & $20.18 \pm 6.13 * *$ \\
\hline M5 $(1 / 4:-)$ & $80.16 \pm 3.21 * *$ & $29.33 \pm 5.12 * *$ \\
\hline M6 (1/4: 1/2) & $135.56 \pm 5.15^{*}{ }_{(0.04)}$ & $51.11 \pm 4.13 * *$ \\
\hline M7 $(1 / 8:-)$ & $132.44 \pm 3.23 *_{(0.02)}^{(0.04)}$ & $149.12 \pm 5.16^{*}{ }_{(0.03)}^{(0.00)}$ \\
\hline M8 $(1 / 8: 1 / 2)$ & $140.11 \pm 4.12 *_{(0.03)}$ & $156.39 \pm 7.50 *{ }_{(0.05)}$ \\
\hline
\end{tabular}

$* p<0.05$ statistically significant differences between the combined-drug-treated and control groups only. $* * P<0.05$ statistically significant differences between the combined-drug-treated group and both the diminazene aceturate and control groups. M1-8 refer to the combinations of Capsicum annuum: DA, diminazene aceturate. The coefficient of variation data is shown as a subscript without a multiplication step.

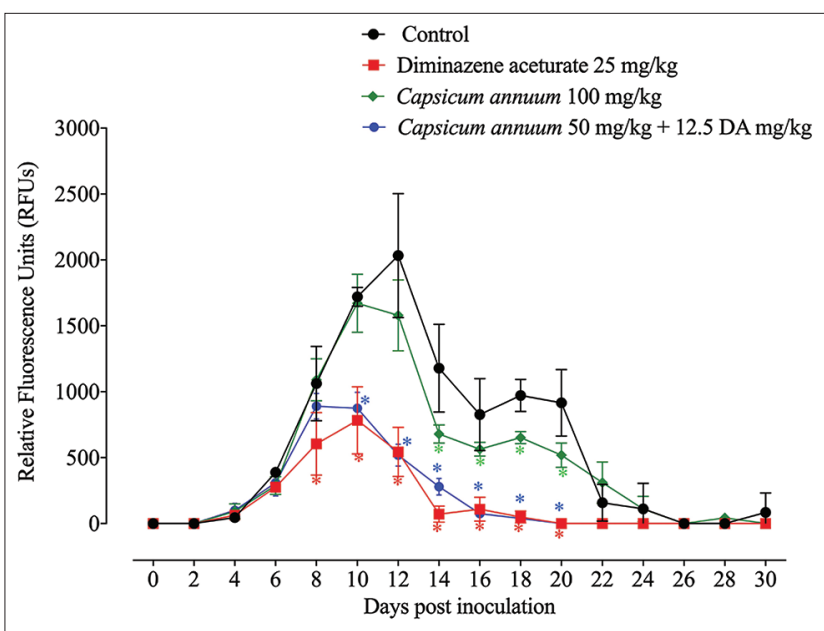

Figure-2: In vivo chemotherapeutic efficacy of Capsicum annuum, diminazene aceturate, and the combination of both drugs on the growth of Babesia microti estimated by the fluorescence assay. Each value represents the mean \pm standard deviation of five mice per experimental group. Asterisks indicate significant differences (analysis of variance; $* p<0.05$ ) between the treated and control groups. allicin [21], fusidic acid [22], and thymoquinone [17]. A significantly high concentration of CA did not affect bovine or horse RBCs in the current examination. This information support CA's non-harmful properties. The issue shows CA's safety in vitro tries and suggests that this promising agent of piroplasm up-and-comer be used in vivo examinations.

Although the in vitro development of Babesia and Theileria parasites was considerably restrained within sight of a high convergence of CA, its inhibitory effects were enhanced when combined with DA. These outcomes are like the in vitro inhibitory effects of myrrh oil/DA [13], allicin/DA [21], and $\mathrm{TQ} / \mathrm{DA}$ combinations [17]. These findings propel us to research the inhibitory effect of CA/DA in mice infected with $B$. microti. Interestingly, the inhibition in B. microti development induced by CA/DA is higher than $70 \%$ inhibition rates for clindamycin combined with quinine [23], 56.35\% and $53.25 \%$ inhibition rates for $85 \mathrm{mg} / \mathrm{kg}$ PYR $/ 10 \mathrm{mg} / \mathrm{kg}$ DA [18], 67\% inhibition rates for $50 \mathrm{mg} / \mathrm{kg}$ enoxacin and $10 \mathrm{mg} / \mathrm{kg} \mathrm{DA}$ [4], and $62.5 \%$ inhibition rates for $50 \mathrm{mg} / \mathrm{kg}$ oral dose of TQ and $10 \mathrm{mg} / \mathrm{kg}$ subcutaneous dose of DA [17].

CA is known as a potent antioxidant agent [8]. Reactive oxygen and nitrogen species (ROS and RNS, respectively) have recently been shown to play a role in the pathogenesis of parasite diseases [24]. Furthermore, parasitic infestations are followed by various oxidant-generating enzymes, which drive the development of various inflammatory cells, which then eliminate intracellular and extracellular parasites [25]. By nitration, oxidation, and chlorination processes, these ROS and RNS are mainly produced to combat invading microorganisms. However, excessive levels of similar reactions might harm host cells and tissue [25]. Infection with Babesia increases the generation of free radicals and oxidative stress markers such as malondialdehyde, protein carbonyl content, and plasma

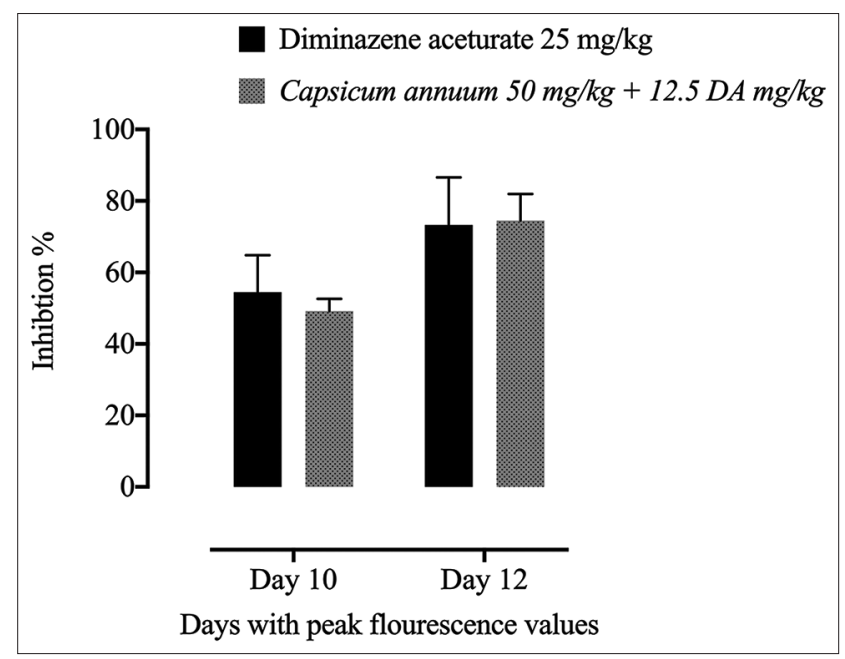

Figure-3: Percentages of inhibition in the growth of $B$. microti in mice caused by diminazene aceturate (DA), Capsicum annuum/DA on the days with peak parasitemia. The $\%$ of parasite inhibition in each treated group was calculated as a ratio to the positive control group. 


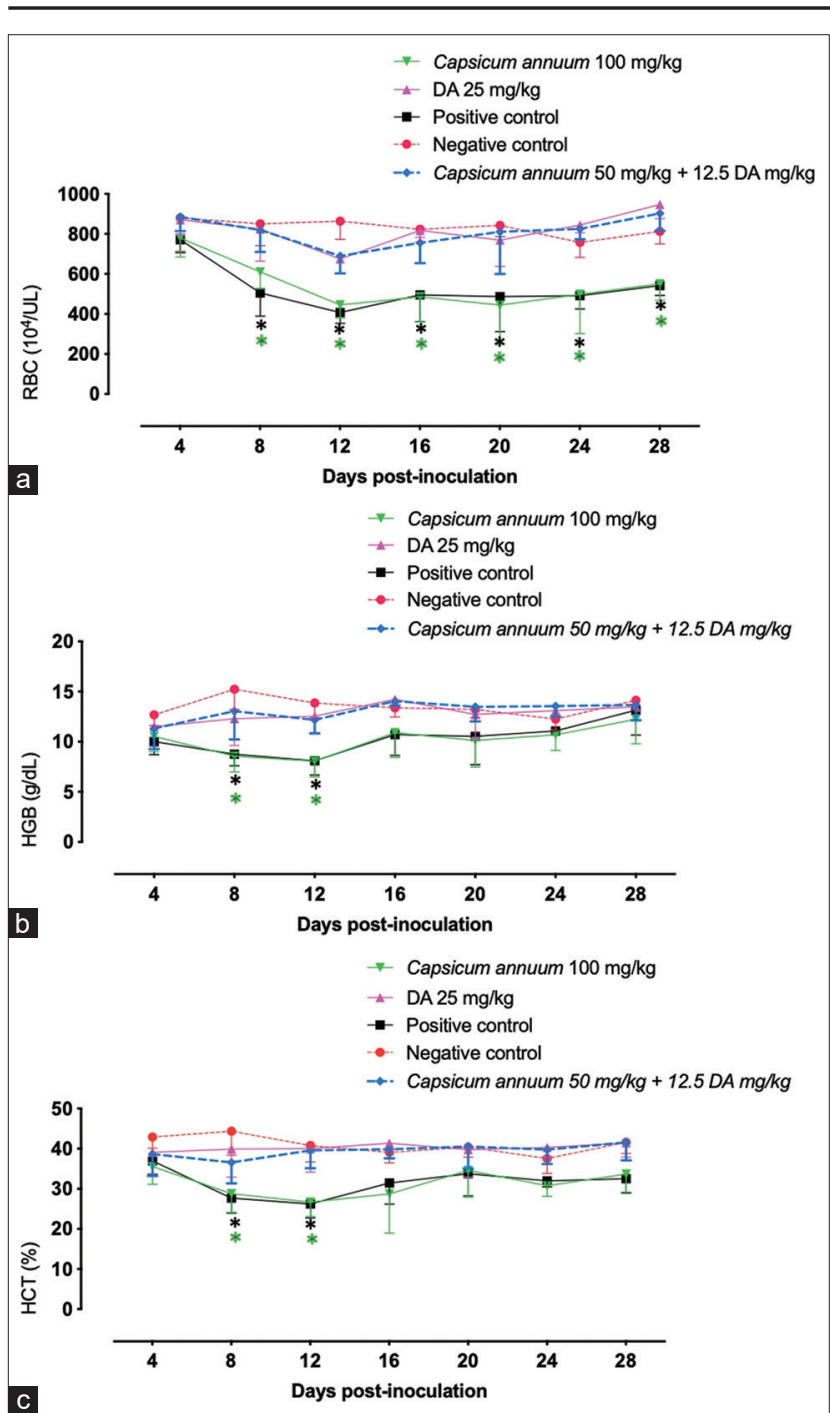

Figure-4: Hematological variables in Babesia microtiinfected mice treated with Capsicum annuum. (a) Red blood cells. (b) Hemoglobin. (c) Hematocrit. Each value represents the mean \pm standard deviation of five mice per experimental group. Asterisks indicate a significant difference (analysis of variance; $* p<0.05$ ) between the treated or infected mice and the uninfected mice.

concentrations of nitric oxide (NOx) metabolites and lowers total antioxidant activity and glutathione levels [26]. Therefore, the CA extract's antibabesial adequacy may be attributed to the potent antioxidant effect of CA. Although this study evaluated the inhibitory effect of methanolic extract of CA against the growth of piroplasm parasites, the study neglected the use of hydroalcoholic extract of CA, which will help in obtaining the polar and non-polar compounds of CA. Therefore, future studies are required to evaluate the inhibitory effect of hydroalcoholic extract of CA against the growth of piroplasm parasites either in vitro or in vivo.

\section{Conclusion}

B. caballi and B. bovis were the most susceptible parasite to the in vitro inhibitory activity of CA. The combination of CA and DA was found to have a potent inhibitory effect on the in vitro growth of $B$. divergens and B. caballi. Mice treated with a combination treatment containing lower doses of $\mathrm{CA}$ and $\mathrm{DA}$ showed an extensive decrease in fluorescence levels. Besides, the CA/DA combination therapy could treat the hemolytic anemia associated with $B$. microti in mice. Such findings show that the CA might be compelling in treating piroplasmosis, especially when combined with a low dose of DA $(12.5 \mathrm{mg} / \mathrm{kg})$.

\section{Authors' Contributions}

MAR, SAEE, and II: Conceptualization. MAR: Data curation. MAR and SAEE: Formal analysis. MAR, II, and MA: Funding acquisition. MAR and II: Investigation. MAR, SAEE, and MA: Methodology. II: Project administration. MAR and II: Resources. MAR: Software. II: Supervision. MAR and II: Validation. MAR and II: Visualization. MAR, SAEE, and MA: Writing of original draft. All authors read and approved the final manuscript.

\section{Acknowledgments}

This study was funded by the Ministry of Education, Culture, Sports, Science, and Technology of Japan. Mohamed Abdo Rizk was supported by a research grant fellowship for young scientists from the Japan Society for the Promotion of Science (JSPS) (ID no. P18091). The authors would like to thank Prof. Naoaki Yokoyama, National Research Center for Protozoan Diseases, Obihiro University of Agriculture and Veterinary Medicine, Inada-cho, Obihiro, Hokkaido, Japan, for his scientific support and discussion.

\section{Competing Interests} interests.

The authors declare that they have no competing

\section{Publisher's Note}

Veterinary World remains neutral with regard to jurisdictional claims in published institutional affiliation.

\section{References}

1. Mosqueda, J., Olvera-Ramirez, A., Aguilar-Tipacamu, G. and Canto, G.J. (2012) Current advances in detection and treatment of babesiosis. Curr. Med. Chem., 19(10): 1504-1518.

2. Rizk, M.A., El-Sayed, S.A.E., El-Khodery, S., Yokoyama, N. and Igarashi, I. (2019) Discovering the in vitro potent inhibitors against Babesia and Theileria parasites by repurposing the Malaria Box: A review. Vet. Parasitol., 274(10): 108895.

3. El-Sayed, S.A.E., Rizk, M.A., Terkawi, M.A., Mousa, A., El Said, E.S.E., Elsayed, G., Fouda, M., Yokoyama, N. and Igarashi, I. (2015) Cocktail of Theileria equi antigens for detecting infection in equines. Asian Pac. J. Trop. Biomed., 5(12): 977-981.

4. Rizk, M.A., AbouLaila, M., El-Sayed, S.A.E., Guswanto, A., Yokoyama, N. and Igarashi, I. (2018) Inhibitory effects of fluoroquinolone antibiotics on Babesia divergens and Babesia microti, blood parasites of veterinary and zoonotic importance. Infect. Drug Resist., 11(9): 1605-1615.

5. (2007) Final report on the safety assessment of Capsicum annuum extract, Capsicum annuum fruit extract, Capsicum annuum resin, Capsicum annuum fruit powder, Capsicum frutescens fruit, Capsicum frutescens fruit extract, Capsicum frutescens resin, and capsaicin. Int. J. Toxicol., 26(1): 3-106. 
6. Maji, A.K. and Banerji, P. (2016) Phytochemistry and gastrointestinal benefits of the medicinal spice, Capsicum annuиm L. (Chilli): A review. J. Complement. Integr. Med., 13(2): 97-122.

7. Kim, W.R., Kim, E.O., Kang, K., Oidovsambuu, S., Jung, S.H., Kim, B.S., Nho, C.W. and Um, B.H. (2014) Antioxidant activity of phenolics in leaves of three red pepper (Capsicum annuum) cultivars. J. Agric. Food Chem., 62(4): 850-859.

8. Sanati, S., Razavi, B.M. and Hosseinzadeh, H. (2018) A review of the effects of Capsicum annuиm L. and its constituent, capsaicin, in metabolic syndrome. Iran. J. Basic. Med. Sci., 21(5): 439-448.

9. Barceloux, D.G. (2009) Pepper and capsaicin (Capsicum and Piper species). Dis. Mon., 55(6): 380-390.

10. Frischkorn, C.G.B., Frischkorn, H.E. and Carrazzoni, E. (1978) Cercaricidal activity of some essential oils of plants from Brazil. Naturwissenschaften, 65(9): 480-483.

11. Al-Asmari, A.K., Albalawi, S.M., Athar, M.T., Khan, A.Q., Al-Shahrani, H. and Islam, M. (2015) Moringa oleifera as an anti-cancer agent against breast and colorectal cancer cell lines. PLoS One, 10(8): e0135814.

12. Kamkar Asl, M., Nazariborun A. and Hosseini M. (2013) Analgesic effect of the aqueous and ethanolic extracts of clove. Avicenna J. Phytomed., 3(2): 186-192.

13. AbouLaila, M., El-Sayed, S.A.E., Omar, M.A., Al-Aboody, M.S., Aziz, A.R.A., Abdel-Daim, M.M., Rizk, M.A. and Igarashi, I. (2020) Myrrh oil in vitro inhibitory growth on bovine and equine piroplasm parasites and Babesia microti of mice. Pathogens, 9(3): 173.

14. Rizk, M.A., El-Sayed, S.A., Terkawi, M.A., Youssef, M.A., El Said, E.S.E., Elsayed, G., El-Khodery, S., El-Ashker, M., Elsify, A., Omar, M., Salama, A., Yokoyama, N. and Igarashi, I. (2015) Optimization of a fluorescence-based assay for large-scale drug screening against Babesia and Theileria parasites. PLoS One, 10(4): e0125276.

15. Rizk, M.A., El-Sayed, S.A., AbouLaila, M., Tuvshintulga, B., Yokoyama, N. And Igarashi, I. (2016) Large-scale drug screening against Babesia divergens parasite using a fluorescence-based high-throughput screening assay. Vet. Parasitol., 227(8): 93-97.

16. Rizk, M.A., El-Sayed, S.A.E., Nassif, M., Mosqueda, J., Xuan, X. and Igarashi, I. (2020) Assay methods for in vitro and in vivo anti-Babesia drug efficacy testing:
Current progress, outlook, and challenges. Vet. Parasitol., 279(3): 109013.

17. El-Sayed, S.A.E., Rizk, M.A., Yokoyama, N. and Igarashi, I. (2019) Evaluation of the in vitro and in vivo inhibitory effect of thymoquinone on piroplasm parasites. Parasit. Vectors, 12(1): 37.

18. Rizk, M.A., El-Sayed, S.A.E., AbouLaila, M., Eltaysh, R., Yokoyama, N. and Igarashi, I. (2017) Performance and consistency of a fluorescence-based high-throughput screening assay for use in Babesia drug screening in mice. Sci. Rep., 7(1): 12774.

19. Ajanal, M., Gundkalle, M. and Nayak, S. (2012) Estimation of total alkaloid in Chitrakadivati by UV-spectrophotometer. Anc. Sci. Life, 31(4): 198-201.

20. Truong, D.H., Nguyen, D.H., Ta, N.T.A., Bui, A.V., Do, T.H. and Nguyen, H.C. (2019) Evaluation of the use of different solvents for phytochemical constituents, antioxidants, and in vitro anti-inflammatory activities of Severinia buxifolia. J. Food Qual., 2019(2): 8178294.

21. Salama, A.A., AbouLaila, M., Terkawi, M.A., Mousa, A., El-Sify, A., Allaam, M., Zaghawa, A., Yokoyama, N. and Igarashi, I. (2014) Inhibitory effect of allicin on the growth of Babesia and Theileria equi parasites. Parasitol. Res., 113(1): 275-283.

22. Salama, A.A., Aboulaila, M., Moussa, A.A., Nayel, M.A., El-Sify, A., Terkawi, M.A., Hassan, H.Y., Yokoyama, N. and Igarashi, I. (2013) Evaluation of in vitro and in vivo inhibitory effects of fusidic acid on Babesia and Theileria parasites. Vet. Parasitol., 191(1-2): 1-10.

23. Marley, S.E., Eberhard, M.L., Steurer, F.J., Ellis, W.L., McGreevy, P.B. and Ruebush, T.K. $2^{\text {nd }} .(1997)$ Evaluation of selected antiprotozoal drugs in the Babesia microti-hamster model. Antimicrob. Agents Chemother., 41(1): 91-94.

24. Bildik, A., Kargin, F., Seyrek, K., Pasa, S. and Ozensoy, S. (2004) Oxidative stress and non-enzymatic antioxidative status in dogs with visceral leishmaniasis. Res. Vet. Sci., 77(1): 63-66.

25. Kocyigit, A., Keles, H., Selek, S., Guzel, S., Celik, H. and Erel, O. (2005) Increased DNA damage and oxidative stress in patients with cutaneous leishmaniasis. Mutat. Res., 585(1-2): 71-78.

26. Ince, S., Kozan, E., Kucukkurt, I. and Bacak, E. (2010) The effect of levamisole and levamisole+Vitamin C on oxidative damage in rats naturally infected with Syphacia muris. Exp. Parasitol.,124(4): 448-452.

\section{Supplementary data}

Table-S1: IC $_{90}$ values of Capsicum annuum evaluated for bovine Babesia and equine Babesia and Theileria parasites.

\begin{tabular}{lc}
\hline Organism & IC $_{\mathbf{9 0}}(\mathbf{m g} / \mathbf{m L})^{\mathbf{a}}$ \\
\hline B. bovis & 8.77 \\
B. divergens & 79.40 \\
T. equi & 14.81 \\
B. caballi & 2.27 \\
\hline
\end{tabular}

${ }^{\mathrm{a}} \mathrm{C}_{90}$ values for Capsicum annuum were calculated based on the IC $_{50}$ values obtained from in vitro growth inhibition assay. $B$. bovis $=$ Babesia bovis, $B$. divergens $=$ Babesia divergens, B. caballi=Babesia caballi
Table-S2: Viability test results of diminazene aceturate drug evaluated for Babesia and Theileria parasite.

\begin{tabular}{lccccc}
\hline Drug & \multicolumn{5}{c}{ Drug concentrations $(\boldsymbol{\mu g} / \mathbf{m L})^{\mathbf{a}}$} \\
\cline { 2 - 6 } & $\mathbf{1 0}$ & $\mathbf{5}$ & $\mathbf{1}$ & $\mathbf{0 . 5}$ & $\mathbf{0 . 2 5}$ \\
\hline B. bovis & - & - & - & - & - \\
B. divergens & - & - & - & - & - \\
T. equi & - & - & - & - & - \\
B. caballi & - & - & - & - & - \\
\hline
\end{tabular}

aEach value was calculated using Babesia fluorescence assay (BFA) in three separate experiments. Each concentration of the drug was made in triplicate in each experiment. +=viable; $-=$ dead. $B$. bovis=Babesia bovis, B. divergens $=$ Babesia divergens, $B$. caballi=Babesia caballi, $T$. equi $=$ Theileria equi 